\title{
A INDEPENDÊNCIA É UM MODO DE PRODUÇÃO
}

Alice Bicalho de Oliveira*

RESUMO: A forma do livro se modifica continuamente, seja no plano diacrônico, seja no sincrônico. Tanto quanto ele, os modos de editar são múltiplos e fluídos no que diz respeito às técnicas de impressão, trato com a linguagem, relações de trabalho e comerciais, distribuição etc. A partir de quais critérios, então, estabelecer uma diferenciação entre um modo padrão de edição e modos independentes? Haveria questões e valores que pautariam um modo e não outro? Poderíamos ainda, mais profundamente, estabelecer semelhancas entre modos de trabalho e produtos finais às vezes tão distintos quanto um best-seller um livreto mimeografo? Neste artigo buscamos alguns parametros para pensar a edição independente, indo na direçá da metros para pensar a ediçăo independente, indo na direção da economia do livro, mas, principalmente, do modo de se organizar cada etapa de sua cadeia produtiva.

PALAVRAS-CHAVE: livro; edição; editores independentes; indústria do livro.

\author{
alice.alicebo@gmail.com \\ Doutoranda em Estudos Literários pela Fale-UFMG. Atualmente é \\ professora substituta da formação em edição na graduação em Letras \\ da UFMG.
}

ABSTRACT: The form of the book is continually being modified, be it on the diachronic or on the synchronic plane. So are the publishing possibilities, which are multiple and fluid in terms of printing techniques, dealing with language, work and business relationships, distribution, etc. Thus, from what criteria could it be stablished a differentiation between a standard mode of publishing and the independent modes? Would there be questions and values that could work as a rule for one mode and not for the other? Could we also, in a more thorough way, establish any simlarities between modes of work and end products so different as a bestseller and a mimeographed booklet? In this article we as a bestseller and a mimeographe look for some parameters to think about independent publishing looking at the economy of the book, but mainly, in the way of organizing each stage of its productive chain.

KEYWORDS: book; publishing; independent publishers; book industry. 
"Como todo lo vivo, el libro es indefinible. [...] Un libro se vende, se compra, se cambia, pero no se le debe tratar como una mercancia cualquiera, porque es a la vez múltiple y único, innumerable insustituible."

Robert Escarpit, O livro no mundo atual

Ao realizarmos um levantamento bibliográfico sobre a edição no Brasil, de Hallewell à coleção "Editando o editor", das pesquisas organizadas por Sônia Queiroz sobre editores mineiros ao Editores artesanais brasileiros de Gisela Creni, chama a atenção uma metodologia que parece considerar a experiência individual de cada empresa um fator relevante na construção da memória da área. Além da constituição de uma prosopografia do editor, esse modo de estudo e registro da prática editorial, a partir de entrevistas e dossiês de casas e editores específicos, parece levar em conta a diversidade como um traço da edição. Por outro lado, o estudo comparativo de modos de produzir e pensar esse trabalho pode permitir depreender alguns padrões em circunstâncias espaciais temporais específicas. Assim, quando se avalia os estudos das médias e grandes casas editoriais brasileiras na segunda metade do século XX, algumas preocupações como vendagem expressiva, distribuição massiva, compromisso de "formação cultural" e busca de "qualidade" - esta aparecendo frequentemente como uma exigência cujas características, no entanto, não estão claras nem bem delimitadas - são recorrentes no discurso dos editores. $\mathrm{O}$ estudo detido dessa pluralidade e o depurar de traços comuns poderia ser um ponto de partida para tentarmos determinar um modus operandi da edição comercial brasileira. E, a partir desses padrões, poderíamos pensar modos alternativos ou independentes de editar. A aposta que se pretende pontuar neste artigo segue essas duas direções e, para tanto, analisaremos alguns exemplos que parecem contribuir para uma expansão do conceito de "independência”. No entanto, é preciso, antes, fazer uma breve delimitação de como este termo tem se constituído no nosso imaginário cultural.

Há certa amplidão de definições do termo "independente" no contexto das produções culturais. Um dos sentidos com que, historicamente, a expressão está relacionada consiste nos modos de produção artística e cultural que se realizam desvinculados ou em oposição às grandes empresas da indústria cultural. No que diz respeito ao livro, se tomarmos como exemplo o que na Europa já vinha se organizando desde o século XIX, a indústria se estrutura a partir de grandes - e cada vez maiores - oligopólios ${ }^{1}$ associados a capital de outros tipos de indústria, com tamanha força econômica, que brecam o desenvolvimento de empresas menores e estruturadas com bases diferentes destes acordos comerciais e desta circulação de capital. As transformações expressivas nos modos de produção editorial ocorridas na passagem de
1. Ver MOLLIER. A evolução do sistema editorial francês desde enciclopédia de Diderot $\mathrm{p} .69$. 
2. A esse respeito Mollier fala da importância do projeto editoria da Enciclopédia de Diderot e d'Alembert como uma perspectiva de criação de demanda - em lugar de suprir demandas já existentes até então impensada.

3. MOLLIER. A evolução do sistema editorial francês desde a enciclopédia de Diderot, p. 61, 62. uma produção mecanizada para os desenvolvimentos técnicos posteriores alteraram intensamente o universo editorial, desde a concepção de um projeto de livro a ser publicado ${ }^{2}$ até o estabelecimento dos direitos de autor, tiragens e modos de venda. A partir daí a história do livro vê certos esquemas de cooperação e troca entre editores serem esquecidos, e uma especialização e profissionalização cada vez maiores dos seus atores. Esta tendência não se desfez, pelo contrário, continua a crescer e a receber reforços de outras indústrias, agora das comunicações e tecnologias de informação.

Diante deste universo podemos delimitar um primeiro campo para a compreensão do significado do termo "independente”, qual seja, a oposição a um modelo industrial de produção, de vínculos entre grandes empresas, e de seus acordos financeiros. É por este contexto que em um ensaio publicado na revista Livro, da USP, Jean-Ives Mollier inicia sua reflexão chamando a atenção para o fato de que "a aparição do tipo social que constitui a figura do editor - protótipo do legendário Gaston Gallimard - é rapidamente eclipsado pela emergência subterrânea da empresa editorial, espécie de monstro que assusta os observadores mais lúcidos". ${ }^{3}$ Sob este ponto de vista, a gama de editores que podem se considerar independentes é enorme, especialmente no Brasil, país em que o número de grandes grupos editoriais vinculados a capitais de outros tipos de indústria - nacionais ou internacionais
- organizados em políticas de desenvolvimento do setor é bem inferior ao número de editores que trabalham na base do "cada um por si", sofrendo o enorme impacto da competição desequilibrada com estes poucos (mas) gigantes da edição Nesse sentido, portanto, podemos considerar editores independentes numa escala macroscópica as editoras de grande porte que só se estruturam financeiramente por meio da venda de livros; ${ }^{4}$ em outra escala, os editores de médio e pequeno porte que se organizam em ligas, mas se mantêm independentes em termos de capital e de competição de mercado, ${ }^{5} \mathrm{e}$ microscopicamente uma enormidade de pessoas físicas que produzem livros artesanais e os comercializam em pontos de cultura das grandes cidades. Em outras palavras, esta primeira ideia de "independência" aponta para um modo de relacionamento entre empresas e capitais, não tecendo qualquer relação com o modo de produzir ou o tipo de produto final e, por isso mesmo, permite que coloquemos em um mesmo grupo "de independentes" formas muito distintas de editar e uma gama enorme de livros.

Suplementar a este ponto, a ideia de "independência" toma um sentido ideológico no contexto das artes, das vanguardas, mas também, e principalmente, das "contraculturas". Tanto no que diz respeito a formas de oposição ao capitalismo ou mesmo aos Estados, de modo geral, ou ainda a governos ditatoriais, em específico, os produtores independentes são
4. Isso justifica, por exemplo, o grupo Record se autointitular "o maior grupo independente" da America Latina (ver 70 Anos Grupo Editorial Record. Uma história contada em livros. Disponível em: < https://www.youtube.com/ watch?v=TbRTV Acesso em: 17 jan. 2017); e faz parecer razoável a justificativa elaborada pelos editores da Hachette que pretendiam acalmar os ânimos de pequenos editores prejudicados por este gigante federacão 'Pe PME' (Pequenas médias empresas)" (MOLUIER. A dias uño francês desce a enciclopédia de Diderot, p. 72).

5. O que explica, por exemplo, enorme variedade de tipos de editores que compoem a LIBRE (Liga Brasileira de Editores) e ao de que o trabalho cooperativo é uma forma de relação de independência: "A L Liga Brasileir de Editoras (LIBRE) é uma rede de editoras independentes, que trabalham cooperativamente, pelo fortalecimento de seus negócios, do mercado editorial e da bibliodiversidade" (disponível em: <http://libre.org.br/quem-somos> Acesso em: 17 jan. 2017). 
6. Sobre essas revistas e seus propositos ideológicos, ver $\mathrm{COHN}$ Revistas de inverco. O livro evistas publicadas a longo do século XX com propósitos culturais conhecidos não apenas por um modo de trabalho alternativo, como também pela realização de "produtos" que reflitam esta postura. Aqui "modo de fazer" e "o que fazer" são elementos fundamentais para a compreensão do que pode ser "independente" ou não. Nesse contexto, vemos uma gama inumeráve de publicações independentes - relacionadas a grupos de vanguarda ou de movimentos desdobrados destes no universo da antiarte -, como as inúmeras revistas alternativas publicadas durante todo o século $\mathrm{XX}^{6}$ no Brasil, mais especificamente aquelas das décadas de 1960 a 1980, bem como nas publicações historicamente conhecidas como "marginais", se materializarem como exemplos deste modo de editar.

Talvez seja interessante notar que enquanto as revistas alternativas se propunham abertamente a produzir conteúdos de resistência cultural e política ao status quo, à massificação e ao silenciamento imposto pela ditadura, os poetas marginais e da geração mimeógrafo, ao buscarem um modo de produção alternativo que lhes permitisse bancar e fazer circular seus textos como produtos comercializáveis, marcaram um modo desviante de escrita literária, com relação à até então realizada no país, e definiram um modo independente de editar.

Desde seu surgimento, as práticas de poesia então englobadas pelo rótulo de "marginais" têm sido intensamente estudadas, lidas e debatidas. Como bem observa Heloisa Buarque de Hollanda, esses textos são absolutamente variados em suas formas e não poderiam, em função de estrutura ou linguagem, ser considerados como uma "escola" ou "movimento".

Bem, minha intenção geral foi de reunir num livro "de editor", e portanto num livro que se insinuasse num circuito mais amplo, manifestações isoladas ou praticamente isoladas que eu percebia como importantes no campo da cultura e no campo da literatura. Me foi feita uma encomenda, pela editora Labor do Brasil - já que eu estava trabalhando com esse material havia dois anos -, de reunir os chamados poetas marginais. As dificuldades começaram aí [...] os grupos ou as coleções de distribuição independente se formaram sem obedecer propriamente a programas ou plataformas estéticas ou literárias, mas de uma maneira mais circunstancial, como estratégia de mercado.

O que Heloisa Buarque de Hollanda caracteriza como "estratégia de mercado", uma espécie de luta no campo do "comportamento" - como esta crítica defende na mesma entrevista à revista José em agosto de 1976 -, estaria no rol das semelhanças reais entre poetas de escritas muito distintas. E essa "estratégia" poderia muito bem ser lida sob a ótica da edição. Afinal, se foi o livro 26 poetas hoje, uma publicação oficial, feita por uma grande editora e organizada por uma professora universitária, ${ }^{8}$ o que aparentemente legitimou no universo acadêmico e da grande mídia esses textos, foram os livros
7. HOLLANDA. Poesia hoje, p. 133 Grifo nosso.
EM TESE
BELO HORIZONTE
N. 3
8. Não me proponho a retomar todos os fatos relacionados com as publicaçoes de poetas marginais, dado que há bastante bibliografia confiável sobre o tema. Refiro-me neste caso à publicação de 26 poetas hoje. 
9. Ver observação de Sebastião Uchoa Leite em HOLLANDA. Poesia hoje, p. 133

10. Apesar de haver publicações por exemplo, de Zuca Sardan, das desde a década anterior. independentes e seus modos de publicação e circulação fatores que decididamente diferenciaram a prática dessa geração e demonstraram sua "proposta existencial comum". ${ }^{9}$ Partindo dessa constatação, nos interessa observar o modo como esses livros eram produzidos, modo que arriscamos afirmar, poderiam ser um exemplo limite de edição independente.

Sabemos que nas décadas de $1960^{10}$ a 1980 uma série de poetas - não só os do Rio de Janeiro - produziam livros com recursos mínimos e utilizando, muitos deles, formas de reprodução alternativas ao offset (como a tipografia, o xerox, o silk e o mimeógrafo). Sem ter como objetivo principal alcançar um grande público, realizavam pequenas tiragens que eram vendidas pelos próprios autores em pontos culturais de cada cidade. De modo geral, não havia seleção de autores, mas escolhas mais ou menos coletivas para a elaboração de um original. Assim, quando o responsável por um livro não era seu autor, o editor não cumpria função legitimadora, mas de colaborar para a realização de um projeto. Neste sentido, é expressiva a descrição que Chacal faz da produção de seu Muito prazer e da importância da amizade e das figuras de Guilherme Mandaro e Sérgio Liuzzi:

Eu escrevia a rodo na época. Cada viagem, um caderninho no bolso. E fui preenchendo cadernos de desenho com caneta pilot colorida [...]. Fiz três. Mostrava aos amigos que visitavam a caxanga. Eles incentivavam a publicar. [...] Guilherme perguntou se eu não queria publicar aqueles poemas em mimeógrafo. Ele dava aula de história num curso pré-vestibular [...]. Topei.

Charles fez o dele, Travessa Bertalha, 11, com a ajuda do Guilherme na escolha e organização dos textos. Eu, com a ajuda de Sérgio Liuzzi nos desenhos e na elaboração visual do livreto fiz o meu. [...] Não era fácil desenhar ou escrever sobre o estêncil com um estilete para depois fixa-lo ao mimeógrafo e rodar. A gente só via o resultado depois de impresso.

Com desenhos e caligrafias, o Muito Prazer ficou um pouco mais leve. Fizemos 100 cópias mimeografadas cada um. [...] acabei de grampear os meus e os levei à Escola de Comunicação para mostrar para os colegas de classe. Eles gostaram e perguntaram quanto era. Minha poesia virava mercadoria. E eu precisava vender aquilo para ajudar no aluguel. ${ }^{11}$

A descrição do processo de publicação feita por Chacal dá uma dimensão das condições e expectativas relacionadas a esse tipo de edição. Escrever como prática cotidiana, publicar, a princípio, por perceber o interesse dos pares e finalmente por uma necessidade muito específica: custeio de vida. Todo este contexto pouco "comercial", ao lado da constatação importante: ainda assim estamos aqui falando de uma mercadoria. Esta questão é muito relevante para que não se menospreze que a transformação simbólica (e não só material) do texto em livro não depende da utilização de recursos materiais específicos
11. CHACAL. Uma história à margem, p. 29,30 . 
12. CHACAL. Uma história à margem, p. 52. (um livro não é menos livro por ser mimeografado ou impresso em offset), nem de uma tiragem mínima, nem da aprovação de uma instituição e muito menos da sua circulação ser ampla. A estratégia da venda mão a mão nos contextos de convívio social justifica ao mesmo tempo uma tiragem realista à dimensão pessoal (e não empresarial) do autor-editor, em termos de vínculos sociais, e à dimensão corporal da produção (quantidade de livros humanamente possíveis de serem impressos num mimeógrafo de cursinho pré-vestibular) e da venda (quantos exemplares uma pessoa consegue carregar, se o livro for em formato A5 com média de 30 páginas e em brochura ou se tiver 300 páginas e capa dura?). Esta dimensão corporal aparece como um possível traço do que Chacal diz ser uma junção "da poesia com a vida" que, segundo ele, foi realizada plenamente nas experiências do Nuvem Cigana. A este respeito, cumpre observarmos como os eventos promovidos pelo grupo, como o bloco O Charme da Simpatia, se apresentavam, aos seus idealizadores, como modos despretensiosos de "mudar o mundo através do drible, da batucada e das artimanhas". ${ }^{12}$ Fato é que se não se muda "o" mundo, muda-se mundos. E estes eventos se constituíram como exemplo de transformação de, voltando aos termos de Heloisa Buarque de Hollanda, "estratégia de mercado".

Não é à toa que os livros e revistas feitos pelo Nuvem Cigana ganharam dimensões maiores do que seus suportes impressos.
Os lançamentos, em 1976, de Creme de Lua (Charles), Vau e talvegue (Ronaldo Santos) e Rapto da vida (Bernardo Vilhena) não causaram grande repercussão na época, mas a crise que o grupo tinha em relação ao formato de venda e promoção dos livros fez com que procurassem outras formas de comunicar a poesia. Se os livros não vendiam e circulavam de forma restrita, foi na oralidade do poema e na atmosfera da performance que o Nuvem Cigana marcou a cena cultural da cidade. Suas Artimanhas e o lançamento dos dois Almanaque Biotônico Vitalidade foram eventos multimídia impactantes, realizados pela primeira vez na Livraria Muro e depois no MAM-RJ. Eles detonaram um poderoso processo de trocas culturais. ${ }^{13}$

Tanto o modo de produção - barato, que não exigia grande conhecimento técnico do realizador e que permitia a produção de uma tiragem relevante para o contexto de interesse dos poetas-editores - quanto o modo de divulgação e circulação desses textos - em festas e eventos, como os promovidos pela Nuvem Cigana - aparentemente realizados sem o objetivo de se opor ao modo de trabalho das grandes editoras, estavam construindo um caminho de oposição à "indústria do livro" em alguns aspectos: ao lugar dado ao poeta na produção do livro, à (des)construção de um lugar canônico para o texto literário, a uma espécie de "evolucionismo da técnica", ${ }^{14}$ que coloca a última tecnologia de impressão como superior às anteriores, ao valor dado à tiragem e, consequentemente,
13. COELHO. Quantas margens cabem em um poema? Poesia marginal ontem, hoje e além, p. 30.

14. Falo em evolucionismo da técnica pensando, por exemplo, em ideia semelhante no campo do verbal/ escrito - o "fonocentrismo", de Derrida -, mas principalmente nos códigos de escrita, como o "alfabetocentrismo", teorizado por Barthes. Aqui poderíamos pensar neste evolucionismo como a crença da superação de uma que a tipografia pareca superad pelo linotipo, este por formas mais velozes de impressão como mais flexografia, esta pelo offset e, em última instância, toda a discussão em torno do e-book que pôde, em algum momento, tratar a questão algum momento, tratar a questao
em termos de "superação" do em termos de "superação" do
livro impresso. Sob este ponto de vista evolucionista, a ideia de "bem impresso" parece estar intrinsicamente relacionada à de capacidade de reprodução mais ou menos realista e toma esse realismo como qualidade natural e desejável do impresso. O que gostariamos de chama atenção é que se nas Artes Plásticas o realismo como valor e naturalização já foi intensamente superado, no mundo editorial ele continua ativo e a gera leituras reduzidas e preconceituosas sobre os impressos. 
à expectativa de venda, como demonstradores da qualidade do texto e do universalismo da leitura e finalmente ao modo de comercialização. A produção editorial marginal, mesmo com a "absorção" de seus poetas e textos, posteriormente, pelas grandes editoras, não consta como etapa da história editorial oficial do Brasil, em nenhum livro a que tivemos acesso, mas se apresenta como um modo exemplar de edição independente, pela sua radicalidade.

A proposta de atrelar a ideia de independência a estes pontos - desvínculo da indústria do livro, independência ideológica e modos alternativos de produção - é um ponto de partida para analisarmos uma enorme e variada gama de práticas que se propuseram independentes de algum contexto majoritário específico. Também chama a atenção, com relação ao lugar que ocupa na "história oficial" da edição brasileira, por exemplo, a produção dos folhetos conhecidos como cordel. Poderíamos equalizar o fato de este tipo de edição não ocupar lugar de destaque, por exemplo, em O livro no Brasi (apenas subcapítulos - o primeiro deles se intitulando "Os folhetos populares" - do capítulo "A atividade editorial nos estados no século XX"), pelo fato de este estar organizado basicamente em capítulos que representam empresas específicas de uma indústria maior. Esta explicação, no entanto, nos parece insuficiente, se considerarmos os feitos industriais, as tiragens e a popularização do modo de edição em questão.
Segundo Hallewell, a produção chega a seu ápice na década de 1940 com uma média - na Tipografia São Francisco, de José Bernardo da Silva - de 300 mil exemplares/mês. Assim, não será em função de uma pequena recepção desse tipo de publicação, mas provavelmente do seu "lugar de produção", que poderemos compreender o lugar menor forjado para ele.

Ocupamo-nos até agora de um material cujo principal mercado são as classes média e alta sofisticadas da grande cidade. $\mathrm{Na}$ vastidão do Brasil, existe uma outra indústria editorial, totalmente distinta, cujo público leitor se encontra principalmente entre classes mais humildes das pequenas cidades e da zona rural do país e sobretudo, nas regiões mais pobres e atrasadas. [...] Poderíamos classifica-la como "a literatura popular do subdesenvolvimento”, pois assemelha-se bastante a um padrão encontrado em todo o mundo ocidental - mesmo nos Estados Unidos - antes do início da industrialização.

Sem pretendermos nos alongar nesta questão, sobretudo para deixar claro que não partimos de tais parâmetros, observamos que as colocações de Hallewell podem conduzir a uma interpretação segundo a qual a "classe" à qual pertencessem os produtores e os leitores de uma publicação poderia ser um elemento para se avaliar a independência de uma edição. Não será nessa linha de raciocínio, no entanto, que consideraremos frutífero colocar a discussão, como se verá. 
15. FRANKLIN. Introdução.

16. Segundo Hallewell (O livro no Brasil, p. 648), após queda de $60 \%$ essa indústria ainda produzia una tiragem ícal de 1 milháo

17. FRANKLIN. Introdução.
Parece relevante notar que estamos tomando o cordel também como uma forma de edição independente. Mas, para tanto, é preciso diferenciar a produção até a época áurea da indústria de folhetos na década de 1940 com a popularização de sua produção, a partir da década seguinte. Segundo dados fornecidos por Jeová Franklin, ${ }^{15}$ a mudança da indústria do cordel de Recife para Juazeiro do Norte na década de 1950 determinou uma mudança técnica da matriz de zincografia (não produzida na nova localização) para a xilogravura (graças ao trabalho dos Santeiros que ali já eram realizados). Essa mudança, a princípio, se apresentou como solução viável a um problema técnico e não uma proposta de transformação editorial desejada; mas com o passar do tempo permitiu aos poetas começarem a se tornar também produtores e determinou a queda das tiragens da grande indústria de cordel, como a de José Bernando. ${ }^{16}$

Antes, o poeta, mesmo consagrado, tinha de vender os originais a um editor conhecido ou trocá-lo por cotas de exemplares da $1^{\mathrm{a}}$ edição. Demorava tempos para ter o produto nas mãos. O recuo tecnológico ampliou o número de escritores, artistas da gravura e, logicamente, de folheteiros. ${ }^{17}$

É possível que esta queda da tiragem seja um dos fatores determinantes para as críticas feitas, no início dessa mudança, pelos revendedores de cordel que, insatisfeitos, atribuíam aos traços rústicos da xilo a diferença na vendagem. No entanto, após uma baixa de 20\% (segundo dados de Jeová Franklin) da produção com relação aos seus tempos áureos, a indústria do cordel produzia uma tiragem de 200 mil exemplares por mês, algo absolutamente relevante num país que sempre se ressente da baixa compra de livros. Essa queda se contrapõe, sobretudo, pela democratização da produção. Se em 1920 havia em média vinte editores de cordel em todo o país, a transformação da matriz de produção de capas em uma técnica mais popular contribuiu intensamente para o surgimento do que se conhece como a "segunda geração de cordelistas" (como Dila, J. Borges e Costa Leite) com média de 500 artistas presentes em feiras e praças.

A queda da tiragem das produções industriais se contrabalanceou com o crescimento significativo das tiragens de pequenos (e independentes) poetas editores. A perna cabeluda, O boi de Minas e A morte de Getúlio Vargas estão entre os mais vendidos com tiragens típicas de best-sellers brasileiros: 120 mil, 300 mil e 500 mil em um mês, respectivamente. O boi de Minas chegou a vender mil em um dia.

As transformações no modo de produção são notáveis a partir daí. O número de páginas e os tipos textuais se alteram em função do gosto do público e se estes fatos são de relevo para um estudo da recepção, também o são para a edição, especialmente a independente. Estamos diante de mais um 
exemplo de livretos que, ao serem impressos na contramão do desenvolvimento técnico do seu momento histórico, permitiram que mais pessoas pudessem os editar. Além disso, o uso da xilogravura despertou o interesse de turistas para aquelas publicações e definiu um novo estilo textual, mais curto (em oito ou 16 páginas) e com temática jornalística "Os romances em desuso de 36 ou 48 páginas restaram como símbolo da antiga folheteria". ${ }^{18}$

Como na poesia marginal, o interesse pelo produto ness outra forma, menos "padrão", de impressão e estruturação do livro parece ter sido de grande importância para sua divulgação, interesse do público e vendagem. Apesar das diferenças impressionantes de tiragem entre os dois exemplos de edições independentes, uma característica chama bastante atenção nas duas práticas: o modo de divulgação e venda

J. Borges usava maleta com um tripé. Onde chegava, espalhava os folhetos e cantava o cordel. A história de prender o cordel em barbante nunca existiu. Pendurar como? Não havia lugar para isso. $\mathrm{O}$ folheteiro também não tinha viola para cantar. Fazia como todo vendedor de folheto. Não utilizava instrumento musical. [...] O vendedor de cordel, ou folheteiro, tem de completar as histórias com piadas e fazer comentários enquanto le o poema. Precisa também fazer as trancas, suspendendo a narrativa nas horas certas, e deixar a história no ar. [...] No som das vaquejadas, o som do aboio. Nas histórias de tristeza, entra o som plangente. [...] $\mathrm{O}$ folheteiro inconsciente perdia a sonora. Isso era defeito grave. ${ }^{19}$

Também aqui, como com a Nuvem Cigana, a performance anda ao lado da edição. O exemplo das publicações marginais - na difusão e vendagem mão a mão - e dos cordéis os verdadeiros best-sellers brasileiros - parecem demonstrar que algo da performatividade está intimamente ligado à relação de interesse pelo texto poético e, consequentemente, pelo livro que dá suporte a ele. Esse talvez seja um ponto de grande importância na edição independente: a possibilidade de performar a venda (algo que o fenômeno das feiras de publicação independente parece compreender muito bem). Esta questão merece um estudo mais detido, que não poderemos realizar agora, mas parece ser elemento importante na cadeia do livro, pouco considerado quando se debate a venda de poesia. Ao lado desse traço, que coloca a importância do corpo e da oralidade na circulação do impresso - e, mais que isso, a importância da atuação do vendedor como leitor/ performador e difusor central do texto -, parece de extrema importância também avaliar os custos gerais de produção de livros, e, consequentemente, os preços de capa, da indústria em comparação com as duas formas estudadas neste artigo, e colocarmos lado a lado tais valores com os dos custos de vida e renda per capita média do brasileiro comum. Esses dois 
20. No artigo em questão, o autor apresenta algumas críticas recebidas para esta proposta de gráfico e elabora outros. No contexto que nos propomos, acreditamos que este modelo nos atenda, já que não estamos, por hora, preocupados com ciclos de fatores podem retirar a edição da torre de marfim que costuma atribuir a pouca vendagem da literatura, especialmente, da poesia, única e exclusivamente a questões de interesse capacidade de leitura da recepção.

O fato é que em se tratando de edição, a relação entre técnica e tiragem é essencial. Consequentemente, a relação entre técnica e venda também é. Enquanto as grandes editoras aparentemente trabalham pela difusão massiva do "livro e da leitura", preocupadas - que dizem ser - com a "cultura" letrada do país, são também suas técnicas de impressão - método e custo envolvidos - que de fato determinam que suas tiragens precisem ser grandes (mesmo que essa grandeza se configure numa escala pouco precisa entre mil e milhões de exemplares) para terem custos menores. Essa realidade está intimamente relacionada, mesmo não sendo considerada como algo a ser repensado, com a justificativa dada por muitos editores sobre a dificuldade, e em certa medida até a inviabilidade, de publicar tipos textuais que "não vendem", como a poesia.

Do que pudemos apresentar nesta breve apresentação do problema, podemos propor um método para futuras análises e estudos sobre edição independente. Pode-se, a princípio, definir um gráfico padrão do ciclo produtivo do livro. Poderíamos, por exemplo, partir do modelo proposto por Robert Darnton em "O que é a história do livro? Revisitado", que ele chamou de "circuito das comunicações"20:

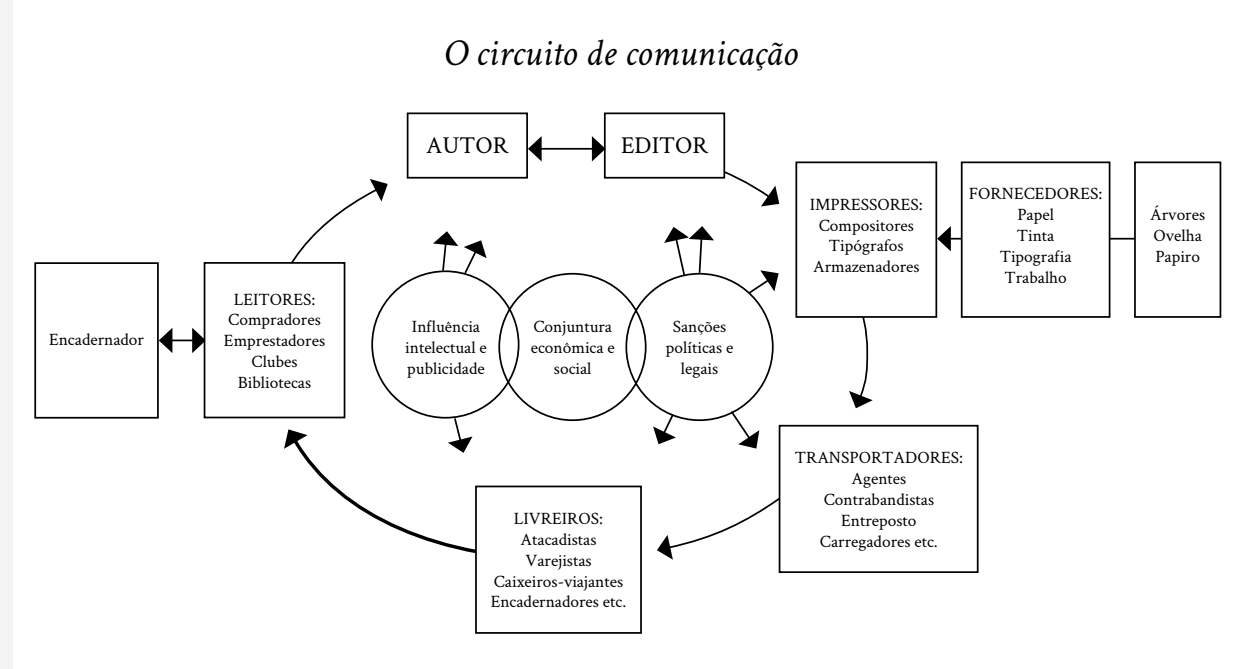

Mesmo que sintamos necessidade de adaptar este modeo a uma realidade contemporânea e brasileira, poderemos verificar em que ponto desse ciclo produtivo os editores são mais ou menos independentes. Em termos gerais, poderemos observar que há formas mais intensamente independentes - como os dois exemplos que consideramos prototípicos do livro marginal e do cordel - e outras menos, para cada uma das etapas, por exemplo, na relação autor \editor, na seleção de originais, no modo de lidar com os direitos autorais, ${ }^{21}$ na escolha das tecnologias de impressão, na relação entre editores e livreiros (sendo muitas vezes uma mesma pessoa, o autor, a ocupar estas duas funções).

Tudo o que delimitamos até aqui faz crer que a "independência” editorial é um fenômeno complexo que pode ser
21. Apesar de não termos tocado nesse ponto anteriormente, cham de grandes pintores em certas publicações marginais e ao mesmo tempo há grandes problemas relacionados ao pagamento de direitos autorais no universo do cordel. 
analisado sob muitos aspectos desde de um ponto de vista da economia global e das relações industriais, como também pela maneira de se diferenciar, ponto a ponto, dos modos padrão de lidar com o fazer e os valores relacionados ao livro e à edição. Do ponto de vista dos gigantes editoriais, editores independentes podem ser colocados como experiências menores, talvez até interessantes ou exóticas, e nunca comparáveis aos seus próprios modelos produtivos, visto por eles próprios como mais desenvolvidos e bem-sucedidos. O que gostaríamos de observar, no entanto, é que essas práticas realizam diferenças na cadeia produtiva e, se nem sempre superam, provocam transformações importantes em dificuldades que as casas editoriais parecem ser incapazes de solucionar, como a divulgação e venda do texto poético. É certo que nossa presente análise não possui elementos suficientes para elaborar conclusões taxativas e generalizadas, mas podemos pensar que o fato de que os editores independentes contam com certa liberdade criativa como parte inalienável do seu trabalho e o fato de que não precisam lidar com uma expectativa de tiragem e distribuição que atenda a ideais "nacionais”, indo numa direção muito menos gregária, possam ser pontos de partida para uma pesquisa mais aprofundada sobre as razões dessas diferenças.

Finalmente, após elencarmos e analisarmos uma ampla gama de diferenças de modo de produção, talvez possamos começar a de fato respeitar a diversidade do setor; dar um xeque-mate em proposições valorativas em hierarquias de melhor ou pior texto, melhor ou pior edição; parar de exigir valores universais em termos da feitura e da distribuição dos livros, e tomar estes últimos por objetos sempre muito específicos desde sua elaboração até sua permanência, ou desaparecimento, no tempo e no espaço.

\section{REFERÊNCIAS}

BARTHES, Roland. Variações sobre a escrita. In: BARTHES,

Roland. Inéditos I. São Paulo: Martins Fontes, 2004. p. 174-255.

CHACAL. Uma história à margem. Rio de Janeiro: 7Letras, 210.

COELHO, Frederico. Quantas margens cabem em um poema? Poesia marginal ontem, hoje e além. In: FERRAZ, Eucanaã (Org.). Poesia marginal: palavra e livro. São Paulo: Instituto Moreira Salles, 2013.

COHN, Sérgio. Revista de invenção. 100 revistas de cultura do modernismo ao século XXI. Rio de Janeiro: Azougue, 2011.

CRENI, Gisela. Editores artesanais brasileiros. Belo Horizonte: Autêntica; Rio de Janeiro: Fundação Biblioteca Nacional, 2013.

DARNTON, Robert. O que é a história do livro? Revisitado. ArtCultura, Uberlândia, v. 10, n. 16, jan.-jun. 2008, p. 155-169.

DERRIDA. Jacques. Gramatologia. São Paulo: Perspectiva, 1973. 
ESCARPIT, Robert; ORTEGA Y GASSET, José. A revolução do

livro. São Paulo: USP, 1971

FILHO, Plínio Martins (Ed.). Coleção editando o editor. São Paulo: Com-arte, 1989.

FRANKLIN, Jeová. Introdução. In: BORGES, J. Cordel

Organização de Jeová Franklin. São Paulo: Hedra, 2007.

(Biblioteca de Cordel).

HALLEWELL, Laurence. O livro no Brasil. 2. ed. rev. e ampl. São Paulo: Edusp, 2005

HOLLANDA, Heloísa Buarque de. Poesia hoje. In: FERRAZ, Eucanaã (Org.). Poesia marginal: palavra e livro. São Paulo: Instituto Moreira Salles, 2013.

MARQUES, Reinaldo Martiniano; VILELA, Lúcia Helena de Azevedo (Org.). Valores: arte, mercado, política. Belo Horizonte, Editora UFMG: Abralic, 2002

MATARELLI, Juliane; QUEIROZ, Sônia (Org.). Editoras mineiras. Panorama histórico v.1. 2. ed. rev. e ampl. Belo Horizonte: FALE UFMG, 2011. (Viva Voz)

MOLLIER, Jean-Ives. A Evolução do sistema editorial francês desde a enciclopédia de Diderot. Livro. Revista do núcleo de estudos do livro e da edição, São Paulo, v. 1, maio 2011.

NOVAES, Adauto (Coord.). Anos 70. Rio de Janeiro: Europa, 1979-80. 